\title{
A complementarity-based equilibrium model of biodiesel market, in Thailand
}

\author{
Somkiat Khwanpruk and Chalida U-tapao* \\ Department of Civil Engineering, Faculty of Engineering, King Mongkut's Institute of Technology Ladkrabang, Bangkok, Thailand
}

\begin{abstract}
This paper presents a complementarity-based model making a decision for energy production in biodiesel market. This model has three strategic players complete against each other on the biodiesel productions. All three players make up biodiesel from agricultural products and they are price-takers. The first player represents producers who produce and sell biodiesel from palm oil. The second and third players produce and sell biodiesel from coconut oil and soybean oil, respectively. The strategic player's decisions involve quantities of palm, coconut and soybean oil related with the market price. This paper uses operation research to optimize a decision maker's objectives within the limits of available agricultural products and also provide results for sustainable energy production.
\end{abstract}

\section{Introduction}

Biodiesel is a significant alternative energy. Ministry of Energy. In Thailand, biodiesel is an alternative renewable energy producing from agricultural products such as palm oil, coconut oil, soybean oil and jatropha oil. Biodiesel produced from agricultural products was about 2,700 million liters (ML) which they were calculated almost 100 percentage of the potential of biodiesel production of Thailand in 2015 [1]. Moreover, Thai population used biodiesel from agricultural product to reduce import 74,964 Million Baht (at present price) Consumption of biodiesel is increased in transportation sector due to demand and supply. Thailand is not a produced petroleum country. As such, Thai government pushes many policies to increase palm, coconut and soybean production and getting oil from them. However, palm, coconut and soybean are also important raw material for various food products. For example, palms are used to produce cooking oil, soybeans are raw materials for human and animal food and coconut is general food. As mention before, palm, coconut and soybean productions are divided into two groups of producers, which are energy and food producers. Therefore, not only prices of raw material for food products prices attract palm, coconut and soybean producers but also biodiesel price is another benefit from these agricultural products.

This paper presents and analyzes a competitive market equilibrium model that can be applied for biodiesel energy market. The decision can help palm oil, coconut oil and soybean oil producers or decisionmakers sell their products to either energy or food producers.

\section{An equilibrium model for biodiesel market}

In what follow, we describe all producer participants including palm oil, coconut oil and soybean oil producers, as well as a detail description of biodiesel market. We also present about decision variables, objective function, constraints, and their associated optimization problem [2].

\subsection{Producer participants and biodiesel market}

Producer participants in this equilibrium model for biodiesel market include palm, coconut and soybean oil producers. Three producers can make a decision on selling palm $\left(q_{p}\right)$, coconut $\left(q_{c}\right)$ and soybean $\left(\mathrm{q}_{\mathrm{s}}\right)$ either to energy producers $\left(q_{p E}, q_{c E}, q_{s E}\right)$ or to food producers $\left(q_{p F}\right.$, $\left.q_{c F}, q_{s F}\right)$, respectively. The growers can decide to sell all their products to energy producers, sell some of them, or don't sell any of them depending on the demand on biodiesel market. Fig. 1 shows flow diagram of palm, coconut and soybean oil to biodiesel market.

\subsection{Decision variables and parameters}

For our work decision variables and parameters as follows [1], [3], [4] and notations below;

$q_{p E}=$ palm oil production (liter)

$q_{c E}=$ coconut oil production (liter)

$q_{s E}=$ soybean oil production (liter)

$q_{b p}=$ biodiesel is produced from palm oil (liter)

$q_{b c}=$ biodiesel is produced from coconut oil (liter)

$q_{b s}=$ biodiesel is produced from soybean oil (liter)

$\pi_{b}=$ biodiesel prices ( $\$$ /iter)

$\gamma_{b p}=$ production costs of biodiesel from palm oil (baht/liter)

$\gamma_{b c}=$ production costs of biodiesel from coconut oil (baht/liter)

$\gamma_{b s}=$ production costs of biodiesel from soybean oil (baht/liter) 
$\bar{q}_{E P}=$ maximum amount of biodiesel is produced from palm oil

$\bar{q}_{E C}=$ maximum amount of biodiesel is produced from coconut oil (liter)

$\bar{q}_{E S}=$ maximum amount of biodiesel is produced from soybean oil (liter)

$$
\begin{aligned}
& b=-6.6823 \\
& a=49.97
\end{aligned}
$$

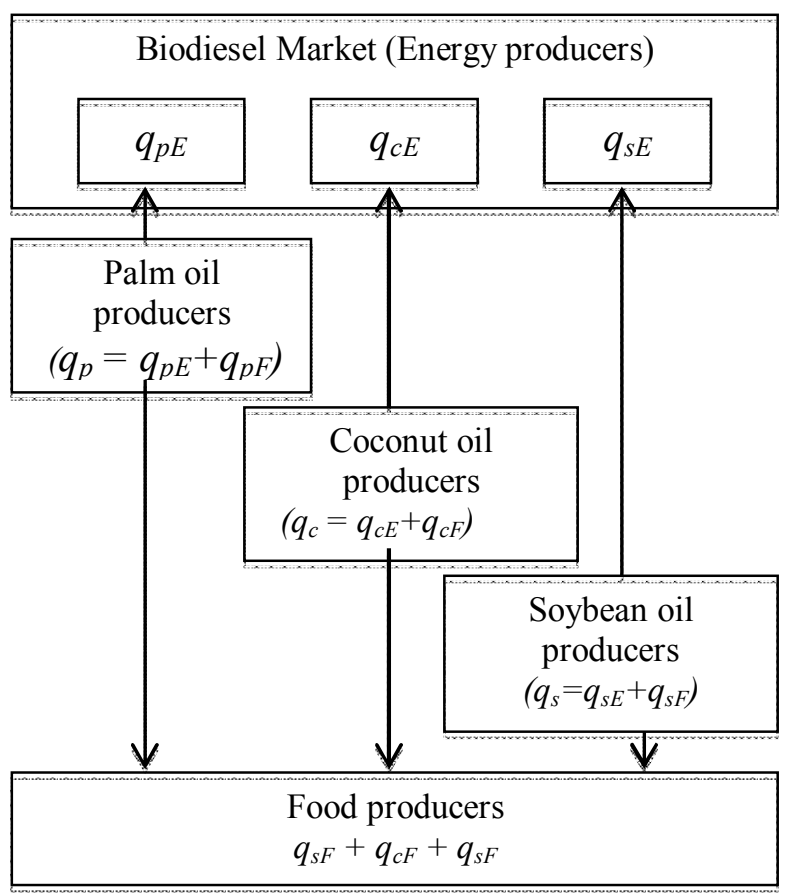

Fig. 1 Flow diagram of palm, coconut and soybean oil to biodiesel market

\subsection{Objective function and constraints}

Objective function of this equilibrium model is to maximize energy producers' profits (revenues minus cots). Three players are involved including producers who produce biodiesel from palm oil (described in (1) and (2)), from coconut oil (described in (3) and (4)) and from soybean oil (described in (5) and (6)). The capacity constraints describe the maximum amount of palm, coconut and soybean oil used to produce biodiesel [5].

$$
\begin{gathered}
\operatorname{Max}_{q_{p E}} \pi_{E} q_{p E}-\gamma_{p E} q_{p E} \\
\text { s.t. } \quad q_{p E} \leq \bar{q}_{p E}\left(\lambda_{p E}\right) \\
\operatorname{Max}_{q_{c E}} \pi_{E} q_{c E}-\gamma_{c E} q_{c E} \\
\text { s.t. } \quad q_{c E} \leq \bar{q}_{c E}\left(\lambda_{c E}\right) \\
\operatorname{Max}_{q_{s E}} \pi_{E} q_{s E}-\gamma_{s E} q_{s E} \\
\text { s.t. } \quad q_{s E} \leq \bar{q}_{s E}\left(\lambda_{s E}\right)
\end{gathered}
$$

Karush-Kuhn-Tucker (KKT) conditions

$$
0 \leq-\pi_{E}+\gamma_{p E}+\lambda_{p E} \perp q_{p E} \geq 0
$$

$$
\begin{aligned}
& 0 \leq \bar{q}_{p E}-q_{p E} \perp \lambda_{p E} \geq 0 \\
& 0 \leq-\pi_{E}+\gamma_{c E}+\lambda_{c E} \perp q_{c E} \geq 0 \\
& 0 \leq \bar{q}_{c E}-q_{c E} \perp \lambda_{c E} \geq 0 \\
& 0 \leq-\pi_{E}+\gamma_{s E}+\lambda_{s E} \perp q_{s E} \geq 0 \\
& 0 \leq \bar{q}_{s E}-q_{s E} \perp \lambda_{s E} \geq 0
\end{aligned}
$$

Market-clearing condition (Supply=Demand)

$$
\pi_{E}=a-b\left(q_{p E}+q_{c E}+q_{S E}\right)
$$

\subsection{Scenarios consideration}

Each scenario considers a combination of three agricultural products. Palm, coconut and soybean productions are separated into three segments. For example, palm production is used to produce biodiesel $100 \%, 50 \%$ and $0 \%$. Energy producers can also produce biodiesel from coconut $100 \%, 50 \%$ and $0 \%$ and soybean are used $100 \%, 50 \%$ and $0 \%$ to produce biodiesel. Therefore, this optimization model considers totally 27 scenarios related with the quantities of each agricultural products. For example, scenario 1 considered $100 \%$ of palm oil (5,169 million liters), $100 \%$ of coconut oil (0.584 million liters) and $100 \%$ of soybean oil $(0.024$ million liters), and scenario 2 considered $100 \%$ of palm oil, $100 \%$ of coconut oil and $50 \%$ of soybean oil, respectively. Fig 2 shows the detail of each scenario.

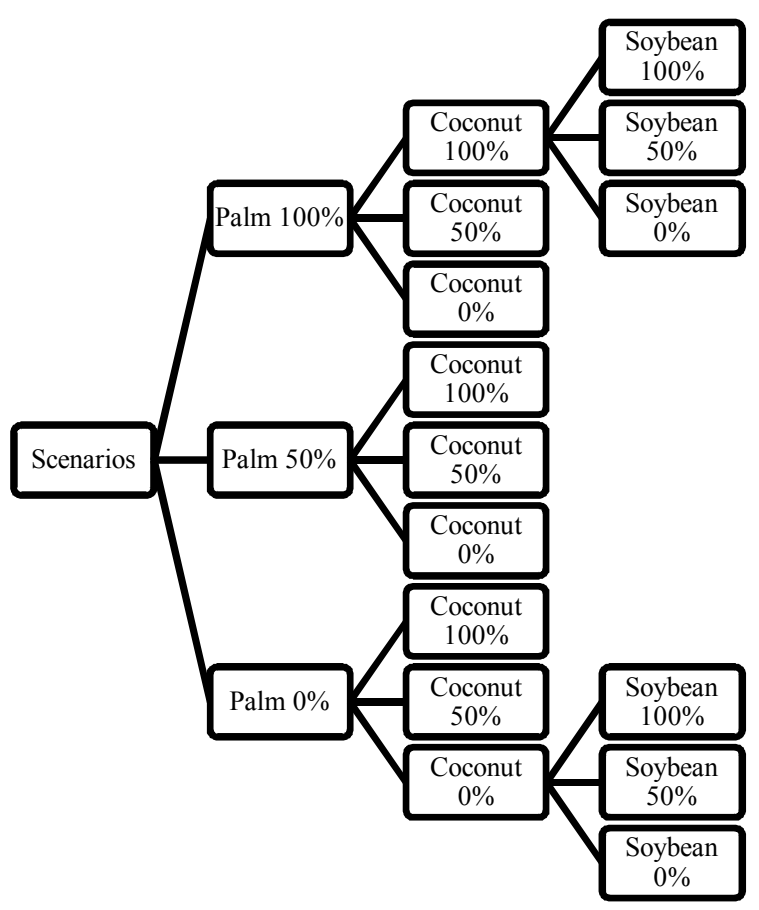

Fig. 2 Detail of consideration scenario 


\section{Result and discussions}

Energy market equilibrium model is shown in this results. The palm oil is always selected to produce biodiesel. The quantity of palm oil was 4.96 million liters and the biodiesel prices was 17.262 baht per liter. Nevertheless, if the quantity of palm oil in the energy market were decreased, coconut oil and soybean oil would affect energy market prices. For example, the energy producers should produce biodiesel from coconut oil and soybean oil if the quantity of palm oil were decreased to $50 \%$ and zero (scenario 10 to 27 ) and coconut oil would affect energy market if the quantity of soybean oil and palm oil decrease to $50 \%$ and zero. The biodiesel prices would increase from 31.926 to 49.890 baht per liter if energy producers had to use coconut oil and/or soybean oil. The maximum amount of coconnut oil and soybean oil were produced biodiesel in order to reduce the demand and the prices for this energy market.

Table 1. Biodiesel prices and quantities of biodiesel form palm oil, coconut oil and soybean oil

\begin{tabular}{|c|c|c|c|c|c|}
\hline Scenario & $\begin{array}{c}\text { Quantities } \\
\text { Palm, Coconut, Soybean oil }\end{array}$ & $\begin{array}{c}q b P \\
\left(10^{6} \text { liters }\right)\end{array}$ & $\begin{array}{c}q b C \\
\left(10^{6} \text { liters }\right)\end{array}$ & $\begin{array}{c}q b S \\
\left(10^{6} \text { liters }\right)\end{array}$ & $\begin{array}{c}\text { Biodiesel prices } \\
\text { (baht/liter) }\end{array}$ \\
\hline 1 & $5,169,435,584,220,24,239$ & 4.9558 & 0 & 0 & 17.262 \\
\hline 2 & $5,169,435,584,220,12,120$ & 4.9558 & 0 & 0 & 17.262 \\
\hline 3 & $5,169,435,584,220,0$ & 4.9558 & 0 & 0 & 17.262 \\
\hline 4 & $5,169,435,292,110,24,239$ & 4.9558 & 0 & 0 & 17.262 \\
\hline 5 & $5,169,435,292,110,12,120$ & 4.9558 & 0 & 0 & 17.262 \\
\hline 6 & $5,169,435,292,110,0$ & 4.9558 & 0 & 0 & 17.262 \\
\hline 7 & $5,169,435,0,24,239$ & 4.9558 & 0 & 0 & 17.262 \\
\hline 8 & $5,169,435,0,12,120$ & 4.9558 & 0 & 0 & 17.262 \\
\hline 9 & $5,169,435,0,0$ & 4.9558 & 0 & 0 & 17.262 \\
\hline 10 & $2,584,718,584,220,24,239$ & 2.5847 & 0.1250 & 0.0242 & 31.926 \\
\hline 11 & $2,584,718,584,220,12,120$ & 2.5847 & 0.1371 & 0.0122 & 31.926 \\
\hline 12 & $2,584,718,584,220,0$ & 2.5847 & 0.1492 & 0 & 31.926 \\
\hline 13 & $2,584,718,292,110,24,239$ & 2.5847 & 0.1250 & 0.0242 & 31.926 \\
\hline 14 & $2,584,718,292,110,12,120$ & 2.5847 & 0.1371 & 0.0122 & 31.926 \\
\hline 15 & $2,584,718,292,110,0$ & 2.5847 & 0.1492 & 0 & 31.926 \\
\hline 16 & $2,584,718,0,24,239$ & 2.5847 & 0 & 0.0242 & 32.751 \\
\hline 17 & $2,584,718,0,12,120$ & 2.5847 & 0 & 0.0122 & 32.751 \\
\hline 18 & $2,584,718,0,0$ & 2.5847 & 0 & 0 & 32.751 \\
\hline 19 & $0,584,220,24,239$ & 0 & 0.5842 & 0.0242 & 45.954 \\
\hline 20 & $0,584,220,12,120$ & 0 & 0.5842 & 0.0122 & 46.034 \\
\hline 21 & $0,584,220,0$ & 0 & 0.5842 & 0 & 46.114 \\
\hline 22 & $0,292,110,24,239$ & 0 & 0.2921 & 0.0242 & 47.882 \\
\hline 23 & $0,292,110,12,120$ & 0 & 0.2921 & 0.0122 & 47.962 \\
\hline 24 & $0,292,110,0$ & 0 & 0.2921 & 0 & 48.042 \\
\hline 25 & $0,0,24,239$ & 0 & 0 & 0.0242 & 49.810 \\
\hline 26 & $0,0,12,120$ & 0 & 0 & 0.0122 & 49.890 \\
\hline 27 & $0,0,0$ & 0 & 0 & 0 & 49.970 \\
\hline
\end{tabular}


Considering at scenario 27 (none of palm oil, coconut oil and soybean oil), the market price was increased to 49.970 baht per liter and alternative sources might be needed to deliver to energy market. All results for each scenario shows in table 1 .

\section{Conclusion}

This equilibrium model presentes energy producers and market. We consider the competitive model for biodiesel energy market in this paper. Three producers complete against each other in energy market. Each player is a price-takers, so the market structure is considered as a perfect competition. This equilibrium problem results when considering the Karush-Kuhn-Tucker (KKT) conditions for optimization problems (maximizing profits of energy producers) faced by energy market participants along with market-clearing condition constraint [5], [6]. The results show that the biodiesel price is reduce (17.262 baht per liter) if farmers sold palm to energy market (5.17 million liters). However, if the quantity of palm used to produce biodiesel is decrease to half and zero, then the market price will be increase. The biodiesel prices can be increased to 31.926, 32.751 and 49.970 baht per liter of biodiesel depended on the amount of palm, coconut and soybean oil in energy market.

\section{References}

1. Development and Efficiency, Ministry of Energy, 2013, Annual report (2012)

2. L. Laokhongthavorn, C. U-tapao, and W. Dejtisakdi, Seventh Annual International Business Heath and Engineering Conference, (Las Vegas, Nevada, USA, 2014)

3. Economic and social development department, Proceedings of the Fiji/FAO Asia Pacific Sugar Conference, (1997)

4. Bank of Thailand, 2012 "Ethanol yearly report 2012", Websit http://www.bot.or.th/Thai/EconomicConditions/Th ai/Northeast/commodities/Doclib_CommodityYear ly/Ethanol\%20Report_2555\%20-last.pdf $>$.

5. S. A Gabriel, S. Kiet, and J. Zhuang., Oper. Res. 53, 799-818 (2005)

6. S. A Gabriel, A. J. Conejo, J. D. Fuller, B. F. Hobbs, and C. Ruiz, Complementarity modeling in energy markets, (Springer, 2010) 